\title{
Thermo-Physical Studies on Molecular Interactions in Liquid Binaries of Diethyl Malonate with Isomeric Xylenes at Different Temperatures
}

\author{
V.N.S.R. VENKATESWARARAO ${ }^{1}$, G. R. SATYANARAYANA ${ }^{2}$, \\ S K. BEEBI ${ }^{3}$ and C. RAMBABU ${ }^{* *}$
}

${ }^{1}$ Department of Chemistry, Acharya Nagarjuna University, Nagarjunanagar, Guntur Dt.-522510, A.P., India

${ }^{2}$ Department of Chemistry, Sir C. R. Reddy PG College, Eluru-534007, A.P., India

${ }^{3}$ Department of Chemistry, Y.V.N.R. Govt. Degree College, Kaikaluru-521333, A.P., India rbchintala@gmail.com

Received 16 October 2017 / Accepted 5 November 2017

\begin{abstract}
Densities and viscosities of binary liquid mixtures of diethyl malonate with isomeric xylenes were reported at different temperature. From the experimental data, deviation in viscosity $(\Delta \eta)$ and excess Gibbs free energy of activation of viscous flow $\left(\Delta \mathrm{G}^{* \mathrm{E}}\right)$ were assessed. The deviations in viscosity and excess Gibbs free energy of activation of viscous flow were correlated with Redlich-Kister polynomial equation. Viscosity theories like Grunberg-Nissan, Katti-Chaudhri, Heric-Brewer, Hind et al., and McAllister four body models have been applied to correlate the viscosity of binary mixtures.
\end{abstract}

Keywords: Density, Viscosity, Gibbs free energy, Molecular collaboration

\section{Introduction}

Density and viscosity play a vital role in analyzing the theoretical and physical properties of binary liquids. The experimental results of these properties of the binary liquids attracted the attention of large number of engineering and chemical industries ${ }^{1}$. The viscosity of binary liquids is a tremendous tool in many chemical applications such as molecular structure, mass, liquid stream, heat transfer and capillary electrophoresis ${ }^{2}$. Moreover, the investigation of excess thermodynamics and transport properties for binary mixture gives essential data concerning the deeper understanding of the molecular liquid structure and intermolecular interactions ${ }^{3}$. Xylenes are habitually utilized as octane enhancer in vehicles ${ }^{4}$. They likewise have different applications in printing, elastic, petrochemical ventures and leather industries. Diethyl malonate (DEM) is a diethyl ester of malonic acid. 
In this study, viscosities and densities are measured at four temperatures (303.15, $308.15,313.15$ and $318.15 \mathrm{~K}$ ) for binary mixtures of diethyl malonate (DEM) with $o$-xylene $(\mathrm{OX}), m$-xylene $(\mathrm{MX})$ and $p$-xylene $(\mathrm{PX})$. Deviation in viscosity $(\Delta \eta)$ and excess Gibbs free energy of activation of viscous flow $\left(\Delta G^{*}\right.$ ) have been computed from density $(\rho)$ and viscosity $(\eta)$ information to understand the nature of forces working between them. Semiempirical viscosity models, for example, Grunberg and Nissan ${ }^{5}$, Katti and Chaudhri ${ }^{6}$, Heric and Brewer ${ }^{7}$, Hind et al., ${ }^{8}$ and McAllister ${ }^{9}$ four body models are utilized to compare the investigational results with the theoretical viscosities.

\section{Experimental}

Diethyl malonate and isomeric xylenes provided from Merck were purified as depicted in the literature $e^{10,11}$. The unadulterated chemicals were stored over activated molecular sieves to decrease water content before utilize. All the binary liquid mixtures are prepared gravimetrically utilizing an electronic balance (Shimadzu AY 120) with an uncertainty of $\pm 1 \times 10^{-7} \mathrm{~kg}$ and stored in sealed shut containers. The uncertainty on mole fraction is evaluated to be $1 \times 10^{-4}$. It is guaranteed that the mixtures are appropriately mixed and the estimation of the required parameters was done within one day of preparation. The densities $(\rho)$ of unadulterated liquids and their mixtures are determined utilizing a $10^{-5} \mathrm{~m}^{3}$ double-arm pycnometer and the values from triplicate replication at every temperature are reproducible within $2 \times 10^{-1} \mathrm{~kg} \mathrm{~m}^{-3}$ and the uncertainty in the estimation of density is observed to be 2 parts in $10^{4}$ parts. The reproducibility in mole fractions was within \pm 0.0002 . Temperature control for the estimation of viscosity and density is accomplished by utilizing a microprocessor assisted circulating water bath regulated to $\pm 0.01 \mathrm{~K}$, utilizing a corresponding temperature controller. Satisfactory precautionary measures were taken to limit evaporation losses during the genuine estimations. Exploratory estimations of density and viscosity at 303.15-318.15 K with those detailed in the literature ${ }^{12-15}$ are provided in Table 1.

\section{Theoretical considerations}

The viscosity deviations $(\Delta \eta)$ were calculated utilizing

$$
\Delta \eta=\eta_{12}-x_{1} \eta_{1}-x_{2} \eta_{2}
$$

Where $\eta_{12}$ is the viscosities of the binary mixture. $x_{1}, x_{2}$ and $\eta_{1}, \eta_{2}$ are the mole fraction and the viscosities of unadulterated segments 1 and 2, respectively. The dynamic viscosities of the liquid mixtures have been computed utilizing observational relations given by Grunberg-Nissan $^{5}$, Katti-Chaudari ${ }^{6}$, Heric-Brewer ${ }^{7}$, Hind et al. ${ }^{8}$, and McAllister ${ }^{9}$ four body models. Grunberg and Nissan ${ }^{5}$ proposed the following equation for the estimation of viscosity of liquid mixtures:

$$
\ln \eta=x_{1} \ln \eta_{1}+x_{2} \ln \eta_{2}+x_{1} x_{2} G_{12}
$$

Where $G_{12}$ is an interaction parameter, which is an element of viscosity of segment liquids 1 and 2 and temperature. Katti and Chaudhri ${ }^{6}$ equation for the dynamic viscosity of the liquid mixture is

$$
\ln [\mu V]=x_{1} \ln \left[\eta_{1} V_{1}\right]+x_{2} \ln \left[\eta_{2} V_{2}\right]+x_{1} x_{2} W_{v i s} / R T
$$

Where $W_{v i s}$ is an interaction term. Heric and Brewer ${ }^{7}$ determined the following equation to calculate the viscosity of the binary liquid mixtures:

$$
\ln \eta=x_{1} \ln \eta_{1}+x_{2} \ln \eta_{2}+x_{1} \ln M_{1}+x_{2} \ln M_{2}-\ln \left(x_{1} M_{1}+x_{2} M_{2}\right)+x_{1} x_{2} \Delta_{12}
$$


Table 1. Comparison of density $(\rho)$ and Viscosity $(\eta)$ of the pure liquids with literature data at $303.15 \mathrm{~K}$

\begin{tabular}{|c|c|c|c|c|c|c|c|c|c|c|c|c|c|c|c|}
\hline \multirow{3}{*}{ 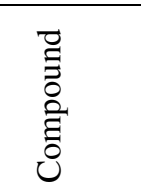 } & \multicolumn{4}{|c|}{$303.15 \mathrm{~K}$} & \multicolumn{4}{|c|}{$308.15 \mathrm{~K}$} & \multicolumn{4}{|c|}{$313.15 \mathrm{~K}$} & \multicolumn{3}{|c|}{$318.15 \mathrm{~K}$} \\
\hline & \multicolumn{2}{|c|}{$\begin{array}{c}\rho \\
10^{-3} \mathrm{~kg} \mathrm{~m}^{-3} \\
\end{array}$} & \multicolumn{2}{|c|}{$\begin{array}{c}\eta \\
\mathrm{mPa} \mathrm{s}\end{array}$} & \multicolumn{2}{|c|}{$\begin{array}{c}\rho \\
10^{-3} \mathrm{~kg} \mathrm{~m}^{-3} \\
\end{array}$} & \multicolumn{2}{|c|}{$\begin{array}{c}\eta \\
\mathrm{mPa} s \\
\end{array}$} & \multicolumn{2}{|c|}{$\begin{array}{c}\rho \\
10^{-3} \mathrm{~kg} \mathrm{~m}^{-3} \\
\end{array}$} & \multicolumn{2}{|c|}{$\begin{array}{c}\eta \\
\mathrm{mPa} s \\
\end{array}$} & \multicolumn{2}{|c|}{$\begin{array}{c}\rho \\
10^{-3} \mathrm{~kg} \mathrm{~m}^{-3} \\
\end{array}$} & $\begin{array}{c}\eta \\
\mathrm{mPas} \\
\end{array}$ \\
\hline & Expt. & Lit. & Expt. & Lit. & Expt. & Lit. & Expt. & Lit. & Expt. & Lit. & Expt. & Lit. & Expt. & Lit. & Expt. \\
\hline $\mathrm{DE}$ & 1.044 & $1.0443^{\mathrm{a}}$ & 1.730 & $1.732^{b}$ & 1.0385 & $1.0387^{\mathrm{a}}$ & 1.602 & $1.602^{\mathrm{b}}$ & 1.0335 & $1.0336^{\mathrm{a}}$ & 1.456 & $1.458^{\mathrm{b}}$ & 1.0313 & & $1.42441 .425^{b}$ \\
\hline$o$-Xylene & 0.8704 & $0.8707^{\mathrm{c}}$ & 0.7061 & $0.7051^{\mathrm{c}}$ & 0.8695 & $0.8694^{\mathrm{c}}$ & 0.665 & $0.6652^{\mathrm{c}}$ & 0.8678 & $0.8677^{\mathrm{c}}$ & 0.6226 & $0.6211^{\mathrm{c}}$ & 0.8658 & $0.8659^{c}$ & $0.5690 .5691^{\mathrm{c}}$ \\
\hline$m$-Xylene & 0.8555 & $0.8557^{\mathrm{c}}$ & 0.5550 & $0.5530^{\mathrm{d}}$ & 0.8485 & $0.8487^{\mathrm{c}}$ & 0.5224 & $0.523^{\mathrm{d}}$ & 0.8455 & $0.8458^{\mathrm{c}}$ & 0.493 & $0.493^{\mathrm{d}}$ & 0.8403 & $0.8405^{\mathrm{c}}$ & $0.46860 .468^{\mathrm{d}}$ \\
\hline$p$-Xylene & 0.8529 & $0.8529^{\mathrm{e}}$ & 0.577 & $0.5782^{c}$ & 0.8468 & $0.8460^{\mathrm{c}}$ & 0.551 & $0.5501^{\mathrm{c}}$ & 0.8428 & $0.8430^{\mathrm{c}}$ & 0.505 & $0.5065^{\mathrm{c}}$ & 0.837 & $0.8369^{\mathrm{c}}$ & $0.4920 .4912^{\mathrm{c}}$ \\
\hline
\end{tabular}

$a=\operatorname{Ref[12],} b=\operatorname{Ref[13],} c=\operatorname{Ref[14]}, d=\operatorname{Ref[15],} e=\operatorname{Ref[16]}$ 
Where $\Delta_{12}$ is association term and other symbols have their typical importance. The expression to determine the viscosity of the binary liquid mixtures proposed by Hind et al. ${ }^{8}$ is given by

$$
\eta=x_{1}^{2} \eta_{1}+x_{2}^{2} \eta_{2}+2 x_{1} x_{2} H_{12}
$$

Where $\mathrm{H}_{12}$ is an association term. McAllister ${ }^{9}$ four body interaction model was generally used to correlate kinematic viscosity $(v)$ information. The two parameter McAllister equation based on Eyring's theory of absolute reaction rates, considered collaborations of both like and unlike molecules by a two dimensional four body model. The four body model was characterized by the connection,

$$
\begin{aligned}
& \ln v=x_{1}^{4} \ln v_{1}+4 x_{1}^{3} x_{2} \ln X_{1112}+6 x_{1}{ }^{2} x_{2}{ }^{2} \ln Z_{1122}+4 x_{1} x_{2}{ }^{3} \ln Z_{2221}+x_{2}{ }^{4} \\
& \ln v_{2}-\ln \left[x_{1}-x_{2}\left(M_{2} / M_{1}+4 x_{1}^{3} x_{2} \ln \left[3+M_{2} / M_{1}\right) / 4\right]+6 x_{1}{ }^{2} 2 x_{2}{ }^{2}\right. \\
& \ln \left[\left(1+M_{2} / M_{1}\right) / 2\right]+4 x_{1} x_{2}{ }^{3} \ln \left[\left(1+3 M_{2} / M_{1}\right) / 4\right]+x_{2}{ }^{4} \ln \left(M_{2} / M_{1}\right)
\end{aligned}
$$

Where $\mathrm{Z}_{1112}, \mathrm{Z}_{1122}$ and $\mathrm{Z}_{2221}$ are model parameters and $M_{i}$ and $\nu_{\mathrm{i}}$ are the molecular mass and kinematic viscosity of pure component i. To perform a numerical comparison of the correlating capability of above equations, we have calculated the standard percentage deviation $(\sigma \%)$ utilizing the connection,

$$
\sigma \%=\left[1 /\left(\eta_{\exp t}-k\right) \times \sum\left(100\left(\eta_{\exp t}-\eta_{\text {cal }}\right) / \eta_{\exp t}\right)^{2}\right]^{1 / 2}
$$

Where $\mathrm{k}$ speaks to the quantity of numerical coefficients in the respective equation. These parameters assessed by a non-linear regression analysis based on a least-squares strategy and given their standard percentage deviation $(\sigma \%)$ in Table 5. On the premise of the theories of absolute reaction rates ${ }^{16}$, the excess Gibbs free energy of activation of viscous flow was computed by utilizing the connection

$$
\Delta G^{* E}=R T\left[\ln \left(\eta V_{m}\right)-x_{1}\left(\ln \eta_{1} V_{1}\right)-x_{2}\left(\ln \eta_{2} V_{2}\right)\right.
$$

Where $\eta$ and $V_{\mathrm{m}}$ are the dynamic viscosity and molar volume of the mixture. $\eta_{1}, \eta_{2}$ and $V_{l}, V_{2}$ are viscosity and molar volume of pure components 1 and 2 individually. $R$ is the real gas constant and $T$ is the absolute temperature. The composition dependence of $\Delta \eta$ and $\Delta \mathrm{G}^{* \mathrm{E}}$ $\left(\mathrm{Y}_{\text {cal }}^{\mathrm{E}}\right)$ for each mixture are fitted to Redlich-Kister polynomial equation ${ }^{17}$

$$
Y_{\text {cal }}^{E}=X_{1} X_{2} \Sigma^{n}{ }_{i-1} A_{i-1}\left(X_{2}-X_{1}\right)^{i-1}
$$

The coefficients of $A_{i-1}$ in the above equation alongside the standard deviation $\sigma\left(\mathrm{Y}^{\mathrm{E}}\right)$ have been ascertained. These coefficients are the adjustable parameters to get best - fit values of $\mathrm{Y}^{\mathrm{E}}$ cal. The standard deviations $\sigma$ of $\mathrm{Y}^{\mathrm{E}}$ cal was computed by utilizing the connection:

$$
\sigma=\left[\Sigma\left(Y_{\exp t}^{E}-Y_{\text {cal }}^{E}\right)^{2} /(m-n)\right]^{1 / 2}
$$

Where $m$ is the quantity of experimental data points and $n$ is the number of coefficients considered and $\mathrm{Y}^{\mathrm{E}}{ }_{\text {expt }}, \mathrm{Y}^{\mathrm{E}}{ }_{\text {cal }}$ are the values of experimental and calculated property $(\Delta \eta$ and $\Delta \mathrm{G}^{* \mathrm{E}}$ ) separately. 


\section{Results and Discussion}

Diethyl malonate is an aprotic solvent which has a solid inclination to pull electron in carbon- oxygen bond towards itself. It has a dynamic methylene gathering and shows dipoledipole interactions in the unadulterated state. The investigational values of viscosity and computed estimations of deviation in viscosity and excess Gibbs free energy of activation of viscous flow for three binary mixtures (DEM+OX/MX/PX) at various temperatures (303.15, $308.15,313.15$ and $318.15 \mathrm{~K}$ ) are displayed in Table 2. Excess/deviation quantities are correlated by Redlich-Kister ${ }^{17}$ polynomial as an element of temperature. The fitting coefficients $\mathrm{A}_{\mathrm{i}-1}$ for all the three binary mixtures are recorded in Table 3 along with their standard deviation $\sigma$ (root mean square deviation).

Table 2. Viscosity, $\eta$ (m Pa s), deviation in viscosity, $\Delta \eta$ (m Pa s) and excess Gibbs free energy of activation of viscous flow, $\Delta \mathrm{G}^{* \mathrm{E}}\left(\mathrm{J} \mathrm{mol}^{-1}\right)$ for the binary mixtures of diethyl malonate and isomeric xylenes at various temperatures

\begin{tabular}{|c|c|c|c|c|c|c|c|c|c|c|c|c|}
\hline & \multicolumn{3}{|c|}{$303.15 \mathrm{~K}$} & \multicolumn{3}{|c|}{$308.15 \mathrm{~K}$} & \multicolumn{3}{|c|}{$313.15 \mathrm{~K}$} & \multicolumn{3}{|c|}{$318.15 \mathrm{~K}$} \\
\hline $\mathrm{X}_{1}$ & $\eta$ & $\Delta \eta$ & $\Delta \mathrm{U}$ & $\eta$ & $\Delta \eta$ & $\Delta \mathrm{G}^{\mathrm{L}}$ & $\eta$ & $\Delta \eta$ & $\Delta \mathrm{G}^{* \mathrm{E}}$ & $\eta$ & $\Delta \eta$ & $\Delta \mathrm{G}^{* \mathrm{E}}$ \\
\hline \multicolumn{13}{|c|}{ diethyl malonate $+o$-xylene } \\
\hline 0.0000 & 0.706 & .000 & & 0.665 & 0.000 & 0.00 & & 0.000 & & & 0.000 & 0.00 \\
\hline & & & & & & 9.93 & & & & & .046 & 82.21 \\
\hline & & & & & & & & & & & & \\
\hline & & & & & & & & & & & & \\
\hline & 387 & 26 & & & 0.285 & & & & & & & \\
\hline & 1.509 & 0.349 & & & 0.304 & & & 0.2 & & 86 & 0.238 & 39. \\
\hline & 615 & 352 & & & & & & & & & 0.240 & \\
\hline & & & & & & & & & & & 20 & \\
\hline & & & & & & & & & & & & \\
\hline & 4 & & & & & & & & & & .076 & \\
\hline & & & & & 0.000 & 0.00 & & 0.00 & & & & \\
\hline \multicolumn{13}{|c|}{ diethyl malonate $+m$-xylene } \\
\hline & 555 & & & .522 & & & & 0.000 & & & & \\
\hline & 0 & & & & & & & & & & 0.048 & \\
\hline & & & & & & & & & & & 0.103 & \\
\hline & & & & & & & & & & & & \\
\hline & & & & & & & & & & & & \\
\hline & 433 & & & & & & & 0.2 & & & 0.2 & \\
\hline & 55 & & & & & & & 0.276 & & & 0.245 & \\
\hline & 651 & & & & & & & & & & & \\
\hline & & & & & & & & & & & & \\
\hline & & & & & & & & & & & & \\
\hline & 730 & & & & 0.000 & 0.00 & 1.456 & 0.00 & & & & \\
\hline \multicolumn{13}{|c|}{ diethyl malonate $+p$-xylene } \\
\hline & & & & & & & & & & & & \\
\hline & & & & & & & & & & & & \\
\hline & & & & & & & & & & & & \\
\hline & 1.166 & & 0 & & & & & 0.223 & & 918 & 85 & \\
\hline & 1.332 & & & & & & & & & 51 & 0.232 & 972.78 \\
\hline & & & & & & & & & & & & \\
\hline & & & & & & & & & & & & \\
\hline & & & & & & & & & & & & \\
\hline & & & & & & & & & & & & \\
\hline & 1 & 0.1 & 298 & & & & & 0.1 & 282.18 & 1.397 & 0.085 & 263.46 \\
\hline 1.0000 & 1.730 & 0.000 & 0.00 & 1.602 & 0.000 & 0.00 & 1.456 & 0.000 & 0.00 & 1.424 & 0.000 & 0.00 \\
\hline
\end{tabular}


Table 3. Redlich-Kister coefficients $A_{i-1}$ and corresponding standard deviations $(\sigma)$ computed for excess/deviation properties of the binary mixtures of diethyl malonate isomeric xylenes ( $o$-xylene, $m$-xylene, $p$-xylene) at various temperatures

\begin{tabular}{|c|c|c|c|c|c|c|c|}
\hline Property & Temp, K & $\mathrm{A}_{0}$ & $\mathrm{~A}_{1}$ & $\mathrm{~A}_{2}$ & $\mathrm{~A}_{3}$ & $\mathrm{~A}_{4}$ & $\sigma$ \\
\hline \multicolumn{8}{|c|}{ diethyl malonate $+o$-xylene } \\
\hline \multirow[t]{4}{*}{$\Delta \eta(\mathrm{mPa} \mathrm{s})$} & 303.15 & 1.4137 & -0.0236 & 0.2506 & 0.2247 & -1.1151 & 0.0077 \\
\hline & 308.15 & 1.225 & 0.0259 & 0.3229 & 0.0528 & -1.2314 & 0.0057 \\
\hline & 313.15 & 1.1038 & 0.0407 & 0.1659 & 0.0183 & -0.9088 & 0.0069 \\
\hline & 318.15 & 0.9739 & -0.0597 & -0.2052 & 0.1073 & -0.46 & 0.0042 \\
\hline \multirow[t]{5}{*}{$\Delta \mathrm{G}^{* \mathrm{E}}, \mathrm{Jmol}^{-1}$} & 303.15 & 3465.29 & 1253.547 & 1370.517 & 471.6292 & -2093.47 & 13.6779 \\
\hline & 308.15 & 3307.13 & 1293.438 & 1648.547 & 46.7655 & -2884.83 & 12.0507 \\
\hline & 313.15 & 3249.124 & 1273.93 & 1323.686 & 0.4554 & -2381.6 & 17.9204 \\
\hline & 318.15 & 3270.533 & 1110.997 & 395.3116 & 61.7989 & -1486.61 & 10.1959 \\
\hline & & dieth & yl malonate & $+m$-xylene & & & \\
\hline \multirow[t]{4}{*}{$\Delta \eta(\mathrm{m} \mathrm{Pa} \mathrm{s})$} & 303.15 & 1.4268 & -0.0539 & 0.2302 & 0.2311 & -1.0576 & 0.0078 \\
\hline & 308.15 & 1.2339 & 0.0043 & 0.3129 & 0.0502 & -1.179 & 0.0054 \\
\hline & 313.15 & 1.1127 & 0.0198 & 0.1582 & 0.0199 & -0.8612 & 0.0069 \\
\hline & 318.15 & 0.9873 & -0.0972 & -0.2063 & 0.1445 & -0.4366 & 0.0045 \\
\hline \multirow[t]{5}{*}{$\Delta \mathrm{G}^{* \mathrm{E}}, \mathrm{Jmol}^{-1}$} & 303.15 & 4120.746 & 1740.811 & 1707.524 & 758.8105 & -1968.94 & 15.2292 \\
\hline & 308.15 & 3960.967 & 1800.282 & 2018.676 & 212.267 & -2892.19 & 12.0754 \\
\hline & 313.15 & 3876.974 & 1750.618 & 1695.694 & 129.119 & -2486.33 & 19.1586 \\
\hline & 318.15 & 3799.511 & 1470.171 & 587.1788 & 233.1599 & -1372.62 & 11.5816 \\
\hline & & dieth & yl malonate & $+p$-xylene & & & \\
\hline \multirow[t]{4}{*}{$\Delta \eta(\mathrm{m} \mathrm{Pa} \mathrm{s})$} & 303.15 & 1.517 & -0.028 & 0.2076 & 0.2096 & -1.0199 & 0.0068 \\
\hline & 308.15 & 1.3352 & 0.0363 & 0.3368 & 0.0291 & -1.2142 & 0.0055 \\
\hline & 313.15 & 1.1558 & 0.0257 & 0.2 & 0.0019 & -0.9231 & 0.0074 \\
\hline & 318.15 & 1.0615 & -0.0761 & -0.2174 & 0.1295 & -0.4061 & 0.0046 \\
\hline \multirow[t]{4}{*}{$\Delta \mathrm{G}^{* \mathrm{E}}, \mathrm{Jmol}^{-1}$} & 303.15 & 4127.674 & 1735.429 & 1671.676 & 742.463 & -1909.63 & 13.834 \\
\hline & 308.15 & 3965.943 & 1787.299 & 2015.433 & 238.7783 & -2868.52 & 12.3211 \\
\hline & 313.15 & 3885.783 & 1739.739 & 1669.768 & 124.6681 & -2434.53 & 19.3599 \\
\hline & 318.15 & 3808.254 & 1469.713 & 567.8503 & 234.8453 & -1293.3 & 12.192 \\
\hline
\end{tabular}

Viscosity deviation

The value and magnitude of $\Delta \eta$ depend on molecular size and shape of the components in addition to intermolecular forces. It is observed (Table 2) that deviation in viscosity is positive for all the systems (DEM+OX/MX/PX) and at all the temperatures. The absolute value of viscosity deviation of (DEM+OX/MX/PX) systems builds directly and scopes to a greatest incentive at $\mathrm{x}_{1} \sim 0.5440$ for $(\mathrm{DEM}+\mathrm{OX}), \mathrm{x}_{1} \sim 0.5483$ for $(\mathrm{DEM}+\mathrm{MX}), \mathrm{x}_{1} \sim 0.5490$ for (DEM+PX), after which step by step diminishes until pure condition of diethyl malonate is arrived. By and large, negative estimations of $\Delta \eta$ demonstrate the presence of dispersion forces or mutual loss of specific interactions in molecules working in the systems and positive estimations of deviation in viscosity show solid particular collaborations ${ }^{18-21}$. As indicated by Kauzmann and Eyring ${ }^{22}$, the viscosity of a mixture unequivocally relies upon the entropy of mixture, which is connected with the structure of the liquid. Vogel and Weiss ${ }^{23}$ clarified that mixtures with solid communications between various molecules and negative deviations from Raoult's law display positive viscosity deviations while for mixtures with positive deviations of Raoult's law and without particular connections, the viscosity deviations are negative. 
Table 4. Experimental and computed estimations of viscosity, $\eta$ (m Pa s) for the binary mixtures of diethyl malonate $+o$-xylene, diethyl malonate $+m$-xylene, diethyl malonate $+p$ xylene at $303.15 \mathrm{~K}$

\begin{tabular}{|c|c|c|c|c|c|c|}
\hline \multicolumn{7}{|c|}{$303.15 \mathrm{~K}$} \\
\hline $\mathrm{x}_{1}$ & $\eta$ Expt & $\eta \mathrm{GN}$ & $\eta \mathrm{KC}$ & $\eta \mathrm{HB}$ & $\eta \mathrm{H}$ & $\eta \mathrm{Mc}$ \\
\hline \multicolumn{7}{|c|}{ diethyl malonate $+o$-xylene } \\
\hline 0.0000 & 0.706 & 0.706 & 0.706 & 0.706 & 0.706 & 0.706 \\
\hline 0.0812 & 0.875 & 0.850 & 0.850 & 0.849 & 0.888 & 0.873 \\
\hline 0.1658 & 1.051 & 1.009 & 1.009 & 1.008 & 1.060 & 1.036 \\
\hline 0.2542 & 1.236 & 1.181 & 1.181 & 1.180 & 1.218 & 1.188 \\
\hline 0.3465 & 1.387 & 1.356 & 1.357 & 1.355 & 1.362 & 1.324 \\
\hline 0.4430 & 1.509 & 1.525 & 1.525 & 1.524 & 1.488 & 1.441 \\
\hline 0.5440 & 1.615 & 1.672 & 1.673 & 1.673 & 1.593 & 1.540 \\
\hline 0.6498 & 1.696 & 1.783 & 1.783 & 1.784 & 1.674 & 1.624 \\
\hline 0.7608 & 1.722 & 1.838 & 1.838 & 1.840 & 1.727 & 1.690 \\
\hline 0.8774 & 1.724 & 1.823 & 1.824 & 1.825 & 1.748 & 1.731 \\
\hline 1.0000 & 1.730 & 1.730 & 1.730 & 1.730 & 1.730 & 1.730 \\
\hline \multicolumn{7}{|c|}{ diethyl malonate $+m$-xylene } \\
\hline 0.0000 & 0.555 & 0.555 & 0.555 & 0.555 & 0.555 & 0.555 \\
\hline 0.0825 & 0.740 & 0.703 & 0.704 & 0.703 & 0.754 & 0.738 \\
\hline 0.1683 & 0.930 & 0.875 & 0.876 & 0.874 & 0.941 & 0.933 \\
\hline 0.2575 & 1.130 & 1.067 & 1.067 & 1.066 & 1.115 & 1.123 \\
\hline 0.3504 & 1.295 & 1.271 & 1.270 & 1.270 & 1.273 & 1.297 \\
\hline 0.4473 & 1.433 & 1.472 & 1.471 & 1.472 & 1.413 & 1.443 \\
\hline 0.5483 & 1.555 & 1.653 & 1.651 & 1.653 & 1.532 & 1.556 \\
\hline 0.6537 & 1.651 & 1.790 & 1.787 & 1.791 & 1.627 & 1.638 \\
\hline 0.7640 & 1.692 & 1.860 & 1.859 & 1.862 & 1.695 & 1.691 \\
\hline 0.8793 & 1.710 & 1.843 & 1.844 & 1.845 & 1.731 & 1.720 \\
\hline 1.0000 & 1.730 & 1.730 & 1.730 & 1.730 & 1.730 & 1.730 \\
\hline \multicolumn{7}{|c|}{ diethyl malonate $+p$-xylene } \\
\hline 0.0000 & 0.577 & 0.577 & 0.577 & 0.577 & 0.577 & 0.577 \\
\hline 0.0827 & 0.768 & 0.730 & 0.731 & 0.729 & 0.781 & 0.767 \\
\hline 0.1687 & 0.964 & 0.906 & 0.907 & 0.905 & 0.973 & 0.966 \\
\hline 0.2581 & 1.166 & 1.102 & 1.102 & 1.101 & 1.149 & 1.160 \\
\hline 0.3511 & 1.332 & 1.308 & 1.307 & 1.307 & 1.309 & 1.334 \\
\hline 0.4480 & 1.469 & 1.510 & 1.508 & 1.509 & 1.449 & 1.479 \\
\hline 0.5490 & 1.588 & 1.688 & 1.685 & 1.688 & 1.565 & 1.589 \\
\hline 0.6544 & 1.678 & 1.819 & 1.817 & 1.821 & 1.656 & 1.665 \\
\hline 0.7645 & 1.712 & 1.881 & 1.880 & 1.883 & 1.717 & 1.711 \\
\hline 0.8796 & 1.721 & 1.854 & 1.855 & 1.855 & 1.743 & 1.731 \\
\hline 1.0000 & 1.730 & 1.730 & 1.730 & 1.730 & 1.730 & 1.730 \\
\hline
\end{tabular}

The less positive $\Delta \eta$ esteems for diethyl malonate $+o$-xylene system show that associations are weaker over diethyl malonate $+m$-xylene and diethyl malonate $+p$-xylene systems ${ }^{24}$, which recommends that the position of $-\mathrm{CH}_{3}$ groups on the aromatic ring assumes a generous part in choosing the extent $\Delta \eta$ and thus, the order of collaboration between the component molecules of the mixtures. The stereo normality of methyl groups in $o$-xylene is such that the steric repulsion is more. So that the $\Delta \eta$ esteems for $o$-xylene are 
observed to be lower than the $m$-xylene and $p$-xylene. On account of $p$-xylene, the two methyl groups disperse similarly the $\pi$-electron cloud on the benzene ring, in this manner the charge transfer complex development between diethyl malonate and $p$-xylene brings about higher positive $\Delta \eta$ esteems. The diethylmalonate $+p$-xylene mixtures are described by more positive $\Delta \eta$ esteems than the mixtures of diethylmalonate $+m$-xylene and diethylmalonate + $o$-xylene, regardless of the way that $p$-xylene very nearly a zero dipole moment and thus dipole-induced dipole associations are not anticipated. One conceivable explanation behind this could be that $p$-xylene molecule is planar and flat type and can shape closer and parallel $\mathrm{n}-\pi$ complexes with slightest steric hindrance. The $\Delta \eta$ esteems diminish with increment of temperature for all the three systems. This might be clarified as takes after: viscosity is principally the force exhibited by one layer of molecules on the neighbouring layer of molecules. With the temperature rise, the cluster breakage causes weak associations and hence less force is exhibited on the adjacent layers which bring about the bringing down of deviation in viscosities. In this manner, the molecular communication follows the order: $\mathrm{DEM}+\mathrm{OX}<\mathrm{DEM}+\mathrm{MX}<\mathrm{DEM}+\mathrm{PX}$

\section{Excess Gibbs free energy of activation of viscous flow}

The excess Gibbs free energy of activation of viscous flow like viscosity deviation can be utilized to detect molecular communications ${ }^{25}$. The excess Gibbs free energy of activation of viscous flow is positive for (DEM+OX/MX/PX) systems over the whole composition range and at all the temperatures. This shows the nearness of appealing strengths between the constituent molecules in the binary mixtures under examination. $\Delta \mathrm{G}^{* \mathrm{E}}$ values diminishes with temperature ascend for all the three systems. This shows the debilitating of intermolecular communications at hoisted temperatures ${ }^{26}$ and this is might be credited to detachment of related molecules through breakage of clusters both in the mixtures and immaculate solvents.

\section{Analysing viscosity of fluid mixtures by semi observational models}

In this article, we utilize the conditions of Grunberg-Nissan ${ }^{5}$, Katti-Chaudhri ${ }^{6}$, Heric- Brewer ${ }^{7}$, Hind $e t a l^{8}$., furthermore, McAllister ${ }^{9}$ four body models to connect the viscosities of binary mixtures of (DEM+OX/MX/PX). Experimental and computed estimations of viscosity ( $\eta$ ) for the binary mixtures of (DEM+OX/MX/PX) at $303.15 \mathrm{~K}$ are displayed in Table 4. Interaction (adjustable) Parameters computed from Eqs. (2-6) and the relating standard deviations $(\sigma)$ for all the binary mixtures are appeared in Table 5. An examination of information in Table 4 demonstrates that all the observational relations gave a sensible fit, but the viscosity values computed utilizing McAllister ${ }^{9}$ four body models are in great concurrence with the experimental values. Examination of information in Table 5 demonstrates that the estimations of interaction parameters (d) computed from various viscosity theories are positive for the systems: (DEM+OX/MX/PX) at the four distinct temperatures.

As indicated by Fort and Moore ${ }^{27}, \mathrm{G}_{12}$ is dealt with as a precise estimation to discover the quality of association between the components. On the off chance that $\mathrm{G}_{12}$ is positive, at that point the system shows property of solid connection, on the off chance that it is negative; it is having the property of feeble communication. So also, Nigam and $\mathrm{Mahl}^{28}$ inferred that: (i) If $\Delta \eta>0, \mathrm{G}_{12}>0$ and the magnitudes of the above are large then solid particular cooperation's would happen; (ii) If $\Delta \eta<0, \mathrm{G}_{12}>0$ then feeble associations would exist; (iii) If $\Delta \eta<0, \mathrm{G}_{12}<0$ and the extents of both are huge then the dispersion force would be predominant. In the present binary systems (DEM+OX/MX/PX), $\mathrm{G}_{12}$ esteems in the Table 5 are positive and viscosity deviation is positive $(\Delta \eta>0)$ consequently one could state that solid particular cooperation's would display in the present binary mixtures. 
Table 5. Interaction parameters and the corresponding standard deviations $(\sigma)$ for the binary mixtures of diethyl malonate and studied isomeric xylenes at various temperatures

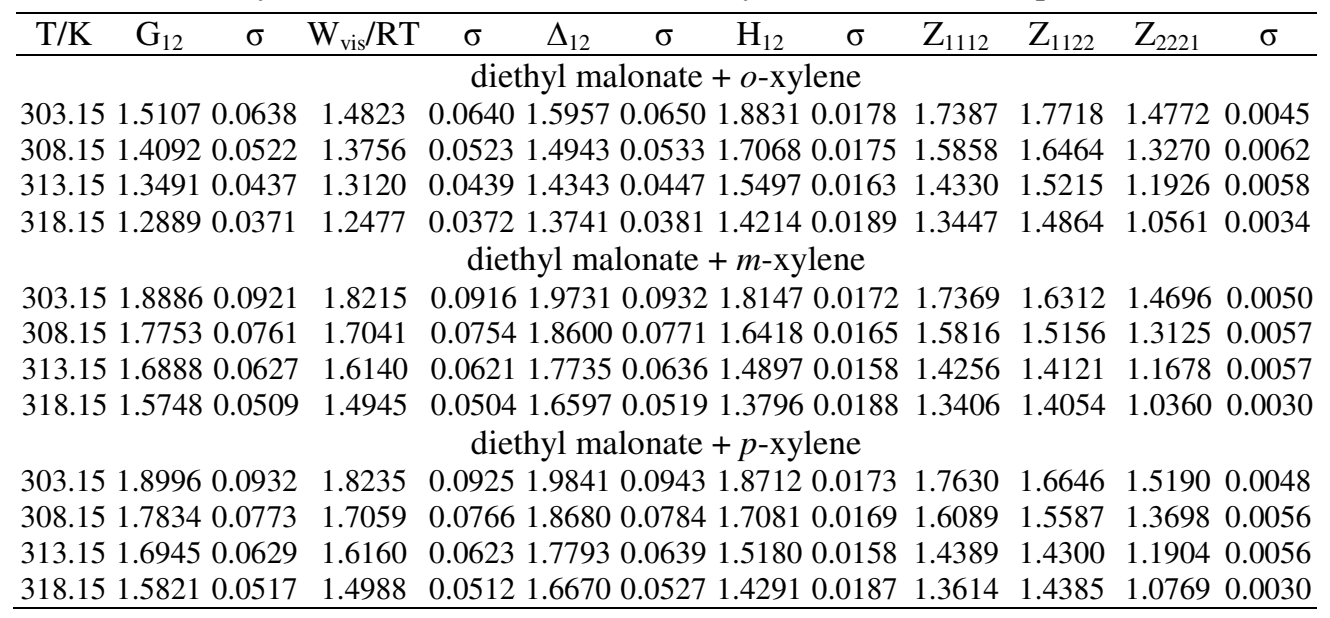

\section{Conclusion}

From the estimations of viscosity and density, deviation in viscosity and excess Gibbs free energy of activation of viscous flow are computed. The exploratory estimations of viscosity were associated with the semi exact relations of viscosity like Grunberg-Nissan ${ }^{5}$, Katti- Chaudhri ${ }^{6}$, Heric-Brewer ${ }^{7}$, Hind et $a l^{8}$ and McAllister ${ }^{9}$ four body models. Among the entire relations McAllister four body model gave great concurrence with the experimental values. From the watched positive estimations of $\Delta \eta, \Delta \mathrm{G}^{* \mathrm{E}}$ and $\mathrm{G}_{12}$ interaction parameter, it is presumed that strong molecular interactions are available among the concentrated binary mixtures.

\section{References}

1. Lal K, Tripathi N and Dubey G P, J Chem Eng Data, 2000, 45(5), 961-964; DOI:10.1021/je000103x

2. Shkolnikov V, Daniel G S, David P F and Juan G S, Sensors Actuators B, 2010, 150(2), 556-563; DOI:10.1016/j.snb.2010.08.040

3. Yang J H, Dai L Y, Wang X Z and Chen Y Q, J Chem Eng Data, 2009, 54(8), 23322337; DOI:10.1021/je900194v

4. Rathnam M V, Mohite S and Kumar M S S, Indian J Chem Tech., 2008, 15, 409-412.

5. Grunberg L and Nissan A H, Nature, 1949, 164, 799-800; DOI:10.1038/164799b0

6. Katti P K and Chaudhri M M, J Chem Eng Data, 1964, 9(3), 442-443; DOI:10.1021/je60022a047

7. Heric E L and Brewer J G, J Chem Eng Data, 1967, 12(4), 574-583; DOI:10.1021/je60035a028

8. Hind R K, McLaughlin E and Ubbelohde A R, Trans Faraday Soc., 1960, 56, 328330; DOI:10.1039/TF9605600328

9. McAllister R A, AIChE Journal, 1960, 6(3), 427-431; DOI:10.1002/aic.690060316

10. Bunger W B, Reddick J A and Sankano T K, Organic Solvents, 3, 4 Edn, Weissberger A, Wiley Interscience, New York, 1986.

11. Furniss B S, Hannaford A J, Smith P W G and Tatchell A R, Vogel's textbook of Practical Organic Chemistry, $5^{\text {th }}$ Edn., Wiley, New York, 1989. 
12. Udayalakshmi Ch, Raj Kumar K A K, Venkateswararao V N S R, Sandhyasri P B, Satyanarayana G R and Rambabu C, Der Pharma Chemica, 2016, 8(5), 209-218.

13. Narendra K, Srinivasu Ch and Narayana Murthy P, J Appl Sci., 2011, 107, 25-30.

14. Jouyban A, Maljaei S H, Soltanpour Sh and Fakhree M A A, J Mol Liq., 2011, 162(2), 50-68; DOI:10.1016/j.molliq.2011.06.002

15. Rathnam M V, Sudhir M and Kumar M S S, Indian J Chem Tech., 2008, 15, 409-412.

16. Glasstone S, Laidler K J and Erying H, The Theory of Rate Process, McGraw-Hill, New York, 1941.

17. Redilch O and Kister A T, Indian Eng Chem., 1948, 40(2), 345-348; DOI:10.1021/ie50458a036

18. Islam M R and Quadri S K, Thermochimica Acta, 1987, 115, 335-344; DOI:10.1016/0040-6031(87)88379-X

19. Tiwari K, Patra C and Chakravortty V, Acoustics Letters, 1995, 19, 53-59.

20. Kondaiah M, Sreekanth K, Kumar D S, Nayeem S M and Rao D K, J Therm Anal Calorim., 2014, 118, 475-483.

21. Bhatia S C, Bhatia R and Dubey G P, J Mol Liq., 2009, 144(3), 163-171; DOI:10.1016/j.molliq.2008.11.003

22. Kauzmann W and Eyring H, J Am Chem Soc., 1940, 62(11), 3113-3125; DOI:10.1021/ja01868a059

23. Vogel H and Weiss A, Ber Bunsenges Phys Chem., 1982, 86(3), 193-198; DOI:10.1002/bbpc.19820860304

24. Rathnam M V and Sudhir M, J Chem Eng Data, 2005, 50(2), 325-329; DOI:10.1021/je0400052

25. Mariano A and Postigo M, Fluid Phase Equilib., 2006, 239(2), 146-155; DOI:10.1016/j.fluid.2005.11.018

26. Satyanarayana G R, Bala Karuna Kumar D, Sujatha K, Lakshmanarao G and Rambabu C, J Mol Liq., 2016, 216, 526-537; DOI:10.1016/j.molliq.2016.01.054

27. Fort R J and Moore W R, Trans Faraday Soc., 1966, 62, 1112-1119; DOI:10.1039/TF9666201112

28. Nigam R K and Mahl B S, Indian J Chem., 1971, 9, 1255-1258. 